\title{
A alegórica Mãe, materno mar angolana e a importância da obra de Boaventura Cardoso na escrita da história de Angola
}

\section{Rafael Cesar (Universidade Federal Fluminense)}

A despeito de ter uma obra ainda pequena frente ao tempo decorrido desde seu livro de estreia, Dizanga dia muenhu, há mais de 30 anos, em termos inversos pode ser notada a produção crítica sobre o escritor angolano Boaventura Cardoso. estudos sobre este original prosador angolano crescem a passos largos e, como escreveu Carmen Lúcia Tindó Secco, tal fenômeno "aponta para a importância do autor no quadro da literatura angolana" (SECCO, apudSANTOS, 2008, p. 9). Corroborando com esta ideia, é muito bem-vinda a publicação de $A$ alegórica 'Mãe, materno mar' angolana, de Olimpia Maria dos Santos. Fruto de uma tese de doutoramento defendida na Universidade Federal do Rio de Janeiro em 2007, o texto de Olimpia dos Santos faz pertinente análise dos três romances de Boaventura Cardoso - a saber, O signo do fogo (1992); Maio, mês de Maria (1997); e Mãe, materno mar(2001) -, propondo uma leitura dos textos mencionados em paralelo à realidade sócio-histórica de Angola na segunda metade do século XX. O percurso feito pela obra romanesca de Boaventura Cardoso parte da hipótese - uso aqui as palavras da própria autora - de que há uma "tecedura alegórica, por meio da qual Boaventura Cardoso repensa a história e as tradições de Angola, propondo-se a revisitá-las criticamente por intermédio do texto ficcional" (SANTOS, 2008, p. 17).

O estudo em questão confirma uma tendência que, em verdade, parte do próprio escritor Boaventura Cardoso. Fica cada vez mais patente a necessidade de ler a sua obra em diálogo com a história recente de Angola, em especial quando se pensam os seus romances. Os três primeiros livros, apenas de contos, instigaram sobretudo à reflexão sobre operações estéticas, o trabalho de linguagem, especialmente o entranhamento das línguas nacionais angolanas com o português, e as várias noções de identidade surgidas a partir desses parâmetros. Já havia nesse momento, certamente, uma relação explícita destes contos com a Angola não-ficcional, mas a construção se dava por cenas mais enxutas e pontuais, pelas histórias pequeninas - caso do menino engraxate obrigado a engolir as ofensas de um homem abastado, marca forte do tempo colonial representada em "Meu toque", de Dizanga dia muenhu, por exemplo. Aquilo que me arrisco a chamar de uma "segunda fase" dentro da obra de Boaventura Cardoso, então composta somente por romances, parece contar já com um distanciamento histórico maior que o leva à construção de enredos mais extensos com vistas a reescrever o processohistórico de modo mais amplo do que fazia com os pequenos 
"episódios" da história que já encontrávamos em seus contos. Olimpia observa esse mesmo fato na introdução de seu texto e justifica-o com palavras do próprio autor em entrevistas colhidas para a pesquisa que fez. Segundo ela, a mudança de gênero adotada na produção ficcional de Boaventura - a troca dos contos pelos romances - se deu em função de poder "abarcar a diversidade de prismas culturais e históricos existentes em sua terra" (SANTOS, 2008, p. 44). Se, por um lado, a afirmação é discutível - o romance não é, necessariamente, um gênero mais "completo" pela sua pura natureza, capaz de maior alcance do que o conto -, por outro, podemos notar também o trabalho de investigação da autora por entender a relevância das motivações de Boaventura Cardoso na moldagem não apenas do conteúdo de seus enredos, mas também da forma de apresentá-los.

A alegórica 'Mãe, materno mar' angolana parte, então, das incontornáveis e conhecidas bases teóricas de estudo do seu tema. A leitura a contrapelo proposta por Walter Benjamin em "Sobre o conceito da história" é a primeira a ser evocada como referência para se chegar às histórias dos "amputados da história", aos textos (quase) apagados da memória social e coletiva. Relacionando sua metodologia ao teórico alemão, Olimpia explica que escolhe a literatura como fonte de cognição porque sua importância é flagrante neste processo de reescritura, como bem fundamenta:

Nas modernas narrativas dos séculos $X X$ e $X X I$, as reminiscências se fazem presentes, pois os discursos enunciadores, ao buscarem uma "outra história", tratam epicamente o narrar, fundando uma ficção que opera com a memória. (SANTOS, 2008, p. 31, grifos meus.)

Aparecem ainda em seu texto, para uma abordagem que se aproxime a perspectivas africanas sobre o tema, Hama Boubou e Joseph Ki-Zerbo; para a conceituação da nova história e a importância da narrativa, Peter Burke, Georges Duby, Jacques Le Goff, Carlo Ginzburg, Linda Hutcheon; dentre outros importantes pensadores.

Após breve visão geral da obra de Boaventura Cardoso e dos pontos metodológicos destacados acima, o texto procede à análise dos três romances de Boaventura. Olimpia organiza seu texto de modo a explorar, em cada um, aspectos do enredo e suas simbologias; as relações presentes entre a Angola ficcional e a Angola extra-ficcional; e finalmente a demonstração da linguagem elaborada pelo autor dentro do seu projeto, seguida da reflexão sobre seu significado. Não podendo dar conta de cada passo feito pela autora de $A$ alegórica 'Mãe, materno mar' angolana, tento aqui destacar alguns aspectos de cada romance trabalhado pela pesquisadora para demonstrar alguns dos pontos mais relevantes de seu trabalho.

No capítulo sobre o primeiro romance de Boaventura Cardoso, $O$ signo do fogo, Olimpia demonstra a recorrência do "fogo" como elemento presente nos textos cardosianos desde a época dos contos até o último romance, e a polissemia do termo ao longo de sua obra. Neste romance, passado na Angola dos anos 60 e 70, e que narra as complexas relações entre colonizados e colonizadores em um momento próximo à independência, o termo "fogo" atravessa o enredo cercado por uma 
multiplicidade de sentidos porque, segundo Olimpia, Boaventura Cardoso não hesita em explorar tanto as raízes simbólicas africanas, como ocidentais, de "fogo". Do ferreiro, homem da lida com o fogo e "personagem enigmático do universo banto-africano", à mitologia grega, com Hefestos, deus do fogo, muitas estão presentes e criam sentidos que, a depender do contexto, podem estar atrelados à intervenção do homem sobre a realidade que o cerca (o fogo como transformação); ao domínio da sabedoria, ou técnica (lembrando Prometeu); ao erotismo; e, ainda, ao de forja da história (cf. SANTOS, 2008, p. 51-71).

Se a cartografia de cada um dos sentidos de fogoseria um trabalho deveras complexo pela já aludida multiplicidade de relações que o termo pode estabelecer, Olimpia escolhe o rumo de uma leitura do significado do fogo pensando justamente o significado da multiplicidade. Através da figura ígnea, então, fica descortinada também aquela que é uma das principais questões das literaturas africanas - e, em geral, de boa parte da produção simbólica de países que têm em sua memória a experiência da colonização: a negociação entre os referenciais simbólicos e culturais da própria terra e da terra do colonizador no forjamentodas identidades, das políticas, da cultura etc. Vejamos como o "fogo" abarca essas questões, segundo Olimpia:

A figura recorrente do ferreiro, em $O$ signo do fogo, assinala a presença do pensamento tradicional africano, impregnado de uma visão mitológica da existência. Por outro lado, ele também é porta-voz das mudanças políticas que se anunciavam e colocavam em cena o marxismo agindo em prol da libertação. Contraditoriamente, os cânones marxista-leninistas não aceitavam a visão animista que caracterizava o pensamento mítico africano. (SANTOS, 2008, p. 86-87)

Analisando Maio, mês de Maria, cujo enredo relata o episódio do movimento separatista ocorrido em maio de 1977 em Angola, posteriormente conhecido como "fraccionismo", vemos a preocupação da autora em abordar o aspecto alegórico construído por Boaventura Cardoso sobre este importante fato político da história de Angola. A ideia é aprofundada por Olimpia dos Santos com uma pertinente comparação. Em $O$ signo do fogo, ela explica, estavam representados os tempos próximos à libertação colonial, dominados pelo sentimento de utopia de matriz marxista-leninista (que se opunha à visão mítica do mundo, como vimos). Uma vez falida a grande promessa em relação ao triunfo do mundo social, a potencialidade das memórias animistas, do universo "mágico-religioso" (aproveitando termo de Carmen Tindó no prefácio a Mãe, materno mar) são reativadas. Para a autora, o fenômeno religioso demonstrado em Maio, mês de Maria (como a manifestação de espíritos identificada pelos fieis na fala do padre, por exemplo), é um indicativo da força das religiões como "tábua de salvação diante desse contexto histórico, cheio de conflitos graves" (SANTOS, 2008, p. 134). A autora faz uma leitura em semelhante linha para elucidar a representação do fenômeno da expansão das igrejas neopentecostais em Angola, mote de Mãe, materno mar, romance seguinte de Boaventura. 
Há várias formas de se ler o fenômeno religioso pentecostal vivido em Angola. Olimpia segue pelo caminho que considera como principal motor de expansão da emergência das tais igrejas eletrônicas o fato de que

Os marginalizados ganham vez e voz, nessas igrejas. A carestia da vida, o desemprego, os conflitos afetivos, as doenças, as frustrações, as opressões, em síntese, problemas vivenciados no dia-a-dia ganham espaço e recebem atenção. Não mais por meio de discursos herméticos como nas religiões cristãs tradicionais, mas por intermédio de palavras simples. (SANTOS, 2008, p. 188)

A abordagem escolhida pela autora dá um tom sociológico para a representação do fenômeno no texto literário, destacando, como se vê, as vulnerabilidades dos grupos subalternos, exploradas pelas igrejas em busca do lucro. Olimpia ainda afirma que é pelo sucesso da oratória dos pastores que se conseguia despertar nos adeptos um estado de "exaltação e histerismo", usando termos da narrativa do próprio Boaventura Cardoso. É evidente que, como em qualquer texto, outras interpretações podem ser feitas. Olimpia não chega a explorar um lado que considero importante para se compreender a representação do fenômeno das igrejas eletrônicas presentes no texto de Boaventura - e sobretudo para essa proposta de diálogo com a história a que ela se propõe -, ligado menos a uma perspectiva sociológica e algo materialista, e mais a aspectos relacionados à memória cultural da coletividade representada em Maio, mês de Mariae em Mãe, materno mar (que não fica de fora em seu texto crítico, mas à qual é dada menor importância). Valendo-se do texto $A$ cultura tradicional bantu, do padre Altuna, Olímpia diz que os pastores conseguem enxertar o seu discurso nos fiéis a partir do que ela chama de "tendências naturais" (SANTOS, 2008, p. 189) dos mesmos, referindose, ao que parece, a essa memória cultural que considerava a efetiva presença do plano divino (chamado de "invisível", para os bantus) em suas vidas.

Parece-me apenas que, para se fazer uma relação entre história e literatura, é preciso considerar também que a "denúncia" da expansão de tais igrejas não se dá nos textos de Boaventura asomente para demonstrar as carências materiais da população angolana, mas sobretudo para evidenciar a força de uma cosmogonia ligada à religiosidade na determinação dos caminhos de Angola - seja em um fato político, como o fraccionismo representado em Maio, mês de Maria, seja no caminhar do país, representado pelo trem descarrilado de Mãe, materno mar. Isto porque, como indica Muniz Sodré em $O$ terreiro e a cidade, falando de alguns fenômenos culturais de matriz africana ocorridos na diáspora,

Essa Arkhé [negro-africana] não implica a revelação de uma verdade eterna ou de relações matematizáveis, mas a possibilidade de se contarem outras histórias sobre a essência do mundo, sobre a gênese e o destino dos homens e das coisas, logo, sobre novas possibilidades 
de transação com a História. A Arkhénegra (...) se insere na História da quotidianidade (...) como um "contralugar" (em face daqueles produzidos pela ordem hegemônica) concreto de elaboração de identidade grupal e de penetração em espaços intersticiais do bloco dirigente. Não se trata de uma "religião" que exiba uma grande "verdade natural", mas de uma dimensão sagrada que permeia a História (SODRÉ, 1988, p. 102-103).

A partir deste entendimento, uma série de eventos presentes na obra de Boaventura Cardoso toma outra dimensão, evidenciando que alguns aspectos representados na literatura não são "meras" representações, mas demonstram formas de relacionamento dos agentes da história com a sua própria história - relações de que nem sempre a História pode dar conta.

A obra de Boaventura Cardoso se prova rica o suficiente pela multiplicidade de leituras que surgem sobre ela e, como já salientei, o aumento de produção crítica sobre o autor vem espelhar esse fato. Sabido disso, o texto de Olimpia dos Santos não se pretende, em nenhum momento, "definidor" da produção romanesca de Boaventura, e tampouco dotado de recortes originais. Mas, pelas frentes de análise que explora com competência e densidade, e pela amplitude de temas abarcados, $A$ alegórica 'Mãe, materno mar' angolana já pode ser considerado um estudo de referência para aqueles que querem trabalhar com a obra de um dos mais instigantes escritores angolanos do nosso tempo.

\section{REFERÊNCIAS BIBLIOGRÁFICAS}

BENJAMIN, Walter. "Sobre o conceito de história". In Magia e técnica, arte e política. ensaios sobre literatura e história da cultura. Tradução de Sérgio Paulo Rouanet; prefácio de Jeanne Marie Gagnebin. São Paulo: Brasiliense, 1994, p. 222-34.

SODRÉ, Muniz. O terreiro e a cidade a forma social negro-brasileira.

Petrópolis, RJ: Vozes, 1988.

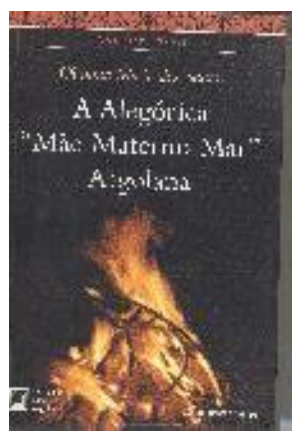

SANTOS, Olimpia Maria dos. A alegórica "Mãe, Materno mar" angolana. Rio de Janeiro/Luanda: Caetés/União dos Escritores Angolanos, 2008. 